\title{
Adjustment disorder in cancer patients after treatment: prevalence and acceptance of psychological treatment
}

\author{
F. E. Van Beek ${ }^{1}$ - L. M. A. Wijnhoven ${ }^{2}$ - J. A. E. Custers ${ }^{2}$ - K. Holtmaat ${ }^{1}$ - B. H. De Rooij ${ }^{3}$ - N. J. E. Horevoorts ${ }^{3,4}$. \\ E. J. Aukema $a^{5} \cdot$ S. Verheul ${ }^{6}$. S. E. J. Eerenstein ${ }^{7}$. L. Strobbe ${ }^{8} \cdot$ I. M. Van Oort ${ }^{9} \cdot$ M. R. Vergeer ${ }^{10} \cdot$ J. B. Prins ${ }^{2}$. \\ I. M. Verdonck-de Leeuw ${ }^{1,7} \cdot$ F. Jansen ${ }^{7}$
}

Received: 28 May 2021 / Accepted: 28 August 2021 / Published online: 2 October 2021

(c) The Author(s) 2021

\begin{abstract}
Purpose To investigate the prevalence of adjustment disorder (AD) among cancer patients and the acceptance of psychological treatment, in relation to sociodemographic, clinical, and psychological factors.

Methods Breast, prostate, and head and neck cancer patients of all stages and treatment modalities $(N=200)$ participated in this observational study. Patients completed the Hospital Anxiety and Depression Scale, Checklist Individual Strength, Distress Thermometer and problem list. Patients with increased risk on AD based on these questionnaires were scheduled for a diagnostic interview. Patients diagnosed with AD were invited to participate in a randomized controlled trial on the cost-effectiveness of psychological treatment. Participation in this trial was used as a proxy of acceptance of psychological treatment. Logistic regression analyses were used to investigate associated factors.

Results The overall prevalence of AD was estimated at $13.1 \%$. Sensitivity analyses showed prevalence rates of AD of $11.5 \%, 15.0 \%$, and $23.5 \%$. Acceptance of psychological treatment was estimated at $65 \%$. AD was associated both with being employed $(\mathrm{OR}=3.3, \mathrm{CI}=1.3-8.4)$ and having a shorter time since diagnosis $(\mathrm{OR}=0.3, \mathrm{CI}=0.1-0.8)$.

Conclusion Taking sensitivity analysis into account, the prevalence of $\mathrm{AD}$ among cancer patients is estimated at 13 to $15 \%$, and is related to being employed and having a shorter time since diagnosis. The majority of cancer patients with AD accept psychological treatment.
\end{abstract}

Keywords Psychology · Cancer · Adjustment disorder · Prevalence · Psychological treatment · Acceptance of psychological treatment

F. Jansen

f.jansen1@amsterdamumc.nl

1 Department of Clinical, Neuro \& Developmental Psychology, Amsterdam Public Health Research Institute, Vrije Universiteit Amsterdam, Amsterdam, The Netherlands

2 Department of Medical Psychology, Radboud Institute of Health Sciences, Radboudumc Nijmegen, Nijmegen, The Netherlands

3 Department of Research, Netherlands Comprehensive Cancer Organisation (IKNL), Utrecht, The Netherlands

4 CoRPS - Center of Research On Psychology in Somatic Diseases, Department of Medical and Clinical Psychology, Tilburg University, Tilburg, The Netherlands

5 Ingeborg Douwes Centrum, Center for Psycho-Oncology, Amsterdam, The Netherlands
6 Department of Medical Psychology, CWZ Nijmegen, Nijmegen, The Netherlands

7 Department of Otolaryngology-Head and Neck Surgery, Cancer Center Amsterdam, Amsterdam UMC, VUmc, PO Box 7057, 1007 MB Amsterdam, The Netherlands

8 Department of Oncological Surgery, CWZ Nijmegen, Amsterdam, The Netherlands

9 Department Urology, Radboudumc Nijmegen, Nijmegen, The Netherlands

10 Department of Radiation Oncology, Cancer Center Amsterdam, Amsterdam UMC, VUmc, Amsterdam, The Netherlands 


\section{Abbreviations}

$\begin{array}{ll}\text { AD } & \text { Adjustment disorder } \\ \text { CIS } & \text { Checklist Individual Strength } \\ \text { DT } & \text { Distress thermometer } \\ \text { NVPO } & \text { Dutch Association for Psycho-oncology } \\ \text { HADS } & \text { Hospital Anxiety and Depression Scale } \\ \text { NCR } & \text { Netherlands Cancer Registry } \\ \text { PROMS } & \text { Patient-reported outcome measures }\end{array}$

\section{Background}

Cancer patients may experience psychological problems [1]. One of these psychological problems is adjustment disorder (AD). According to the Diagnostic and Statistical Manual of Mental Disorders (DSM-V)[2], AD occurs when adaptation to a significant identifiable life stressor, such as cancer, fails.

In a meta-analysis of Mitchell et al. (2011) [3], the prevalence of $\mathrm{AD}$ among cancer patients was estimated at $19.4 \%$ (confidence interval (CI) 14.5-24.8\%). More recent studies showed prevalence rates ranging from 6 to 17\% [4-7]. This variability in prevalence rates may result from methodological differences among studies, as well as from different diagnostic procedures for AD. In the Netherlands, a national guideline on AD has been available since 2016, which includes an assessment procedure for AD diagnosis [8]. Another reason for the observed variation may be that prevalence rates differ among cancer groups. A study of Mehnert et al. [4] showed that the prevalence rate of AD varied between tumor types, with the lowest rate of $2.9 \%$ in rectal cancer patients and the highest rate of $16.5 \%$ in head and neck cancer patients. Other studies demonstrated that patients who were female, more highly educated, diagnosed with a more advanced tumor stage, and living in rural areas, and who lacked physical exercise were more frequently diagnosed with AD [5, 9].

Concerning the usage of psychological treatment, a previous meta-analysis of Brebach et al. [10] showed that $60 \%$ of cancer patients exhibiting distress wanted psychological treatment. A higher usage of psychological treatments was associated with a more recent cancer diagnosis, remote compared to face-to-face treatment and psychological treatment provided by a nurse compared to other psychosocial professionals [9]. Other studies showed that patients who were younger, female, and more highly educated were more likely to accept psychological treatment [11-13]. However, no study so far has focused on the acceptance of psychological treatment for $\mathrm{AD}$ in cancer patients.

In summary, there is inconclusive or limited evidence of the prevalence of $\mathrm{AD}$ and the acceptance of psychological treatment for $\mathrm{AD}$ among cancer patients, as well as its associated factors. The aim of this study was to investigate (1) the prevalence of $\mathrm{AD}$ among cancer patients in relation to sociodemographic and clinical factors; (2) to investigate sociodemographic, clinical, and psychological factors associated with $\mathrm{AD}$ among cancer patients with an increased risk for $\mathrm{AD}$; and (3) to investigate the acceptance of psychological treatment among patients with $\mathrm{AD}$ in relation to sociodemographic, clinical, and psychological factors. Factors associated with AD among cancer patients in general and cancer patients with an increased risk for AD were investigated separately, as patient-reported outcome measures (PROMS) are increasingly used in clinical practice to identify patients with psychological problems. Due to the design of this study, the association between psychological factors and prevalence of AD could only be investigated among patients with an increased risk for AD.

\section{Methods}

\section{Design, participants, and study procedures}

This observational study recruited cancer patients from Amsterdam UMC, Canisius Wilhelmina Hospital and Radboudumc, the Netherlands, between September 2019 and January 2020. The study was part of a randomized controlled trial (RCT) on the effectiveness and cost-utility of tailored psychological treatment targeting cancer patients with $\mathrm{AD}$ [14]. Patients were included, when they (1) were diagnosed with cancer (all types and stages, except non-melanoma skin cancer) between July 2004 and July 2019, (2) were aged $\geq 18$ years, and (3) completed primary cancer treatment with curative or palliative intent (all treatment modalities, except for endocrine therapy in breast and prostate cancer).

Random selections of patients were drawn by the Netherlands Cancer Registry (NCR) which registers all newly diagnosed cancer patients. Recruitment started among breast, prostate, and head and neck cancer patients. Due to the COVID-19 pandemic, patients with other cancer diagnoses could not be recruited. The (former) treating physician checked the eligibility of the patients. After confirming eligibility, a patient information letter with informed consent form was sent to the patient by mail. After consenting, the patient was asked to complete the study questionnaire measuring their risk for $\mathrm{AD}$.

Study procedures were approved by the Medical Ethical Committee of VUmc and followed the Dutch Medical Research Involving Human Subjects Act.

\section{Primary outcome}

The primary outcomes were prevalence of $\mathrm{AD}$ and acceptance of psychological treatment. Prevalence was measured through a two-phase approach including a screening procedure and a diagnostic interview. 
Patients were screened on their risk for $\mathrm{AD}$ using the Hospital Anxiety and Depression Scale (HADS), Distress Thermometer (DT), and problem list. The HADS is a psychometrically validated 14-item self-report questionnaire that measures symptoms of anxiety (HADS-A) and depression (HADS-D) in the last week. Also, a total HADS (HADS-T) score can be calculated ranging from 0 (no distress) to 42 (severe distress) [15]. The DT measures the level of distress experienced in the last week on a scale ranging from 0 (no distress) to 10 (extreme distress) [16]. The problem list measures 47 different problems in the last week, including an item on willingness to talk to an expert, followed by a question on type of expert (psychologist, social worker, dietician, physiotherapist, nurse, peers or other) [16]. Increased risk for AD was defined as HADS-total $\geq 11$ or DT $\geq 4$ or willingness to talk with a psychologist or social worker [14].

Patients with an increased risk for AD were invited for a diagnostic interview either by telephone or face-to-face. The interviews were carried out by trained psychologists, who were registered in the expert database of the Dutch Association for Psycho-oncology (NVPO) or under supervision of a registered psychologist. All psychologists followed an E-Learning program on diagnosis and treatment of AD, which included a reader, videos, and an online assessment $[8,17]$. The E-learning comprised several learning objectives including the definition of $\mathrm{AD}$ among cancer patients and how to describe symptoms along the criteria of the DSM-V. The psychologists completed a form per patient on DSM-V classification of AD (yes/no).

Patients diagnosed with AD were invited by the psychologist to participate in an RCT in which patients received tailored psychological treatment immediately or after a period of 6 months [14]. If a patient was interested in the RCT, a researcher gave further information via telephone and an information letter was sent. In the case that a patient did not respond, they were reminded after 1 week by telephone. Reasons not to participate were reported.

\section{Factors associated with AD and acceptance of psychological treatment}

To investigate factors associated with $\mathrm{AD}$ and acceptance of psychological treatment, the HADS, DT and problem list, the Checklist Individual Strength (CIS) and questions on sociodemographic and clinical characteristics were used. HADS, DT, and problem list are described above. The CIS is a valid and reliable 20-item instrument to measure fatigue, concentration, motivation, and physical activity [18, 19]. A higher score (20-140) indicates a higher level of fatigue.

The socio-demographic questions focused on sex (male/ female), age (years), marital status (yes/no), education level (high/low), and employment status (yes/no). Clinical data (tumor stage (I-II/III-IIII), treatment (single/multiple treatment), and time since diagnosis (less/more than 5 years after diagnosis)) and social economic status (high/middle/ low) were obtained from the NCR.

\section{Statistical methods}

Quantitative analyses were performed using the IBM Statistical package for the Social Science version 26. Descriptive statistics were generated for all baseline characteristics and outcome measures. To investigate selective non-response in phase 1 (screening), respondents and non-respondents were compared using independent $T$-test and chi-square test. In phase 2 (diagnostic interview), participants (those who completed the interview) and drop-outs (those with an increased risk but who did not complete the interview) were also compared. A $p$-value $<0.05$ was considered statistically significant.

To estimate the prevalence of AD among patients, the number of patients diagnosed with $\mathrm{AD}$ was divided by the total number of participants that completed the screening survey minus the total number of drop-outs in phase 2 . In addition, sensitivity analyses were performed in which dropouts of phase 2 were (a) all expected to have AD, (b) partly expected to have $\mathrm{AD}$ (the same prevalence as other patients in phase 2), and (c) all expected to have no AD. To estimate usage of psychological treatment, the number of patients who agreed to participate in the RCT was divided by the total number of patients diagnosed with AD.

Possible factors associated with (1) the prevalence of $\mathrm{AD}$ among all patients and (2) the prevalence of $\mathrm{AD}$ among patients with increased risk and (3) the acceptance of a psychological treatment were investigated using forward logistic regression analyses. Variables were entered one-by-one into the logistic regression model using a $p$-value $<0.05$. Since the HADS, DT, and problem list were used to identify patients with an increased risk for $\mathrm{AD}$, these variables were not entered in the logistic regression models on the prevalence of $\mathrm{AD}$ among all cancer patients.

\section{Results}

\section{Participants}

Figure 1 shows the study flow diagram. Of the 785 cancer patients who were screened for eligibility, 586 patients were invited to participate in the study. There were significant differences between the patients who responded $(N=200$, $34 \%)$ and those who did not respond $(N=386,66 \%)$. Patients who responded were more often male, had a higher social economic status, and were more frequently diagnosed with prostate cancer and more often diagnosed with tumor stage I or II compared to patients who did not respond (Table 1). 


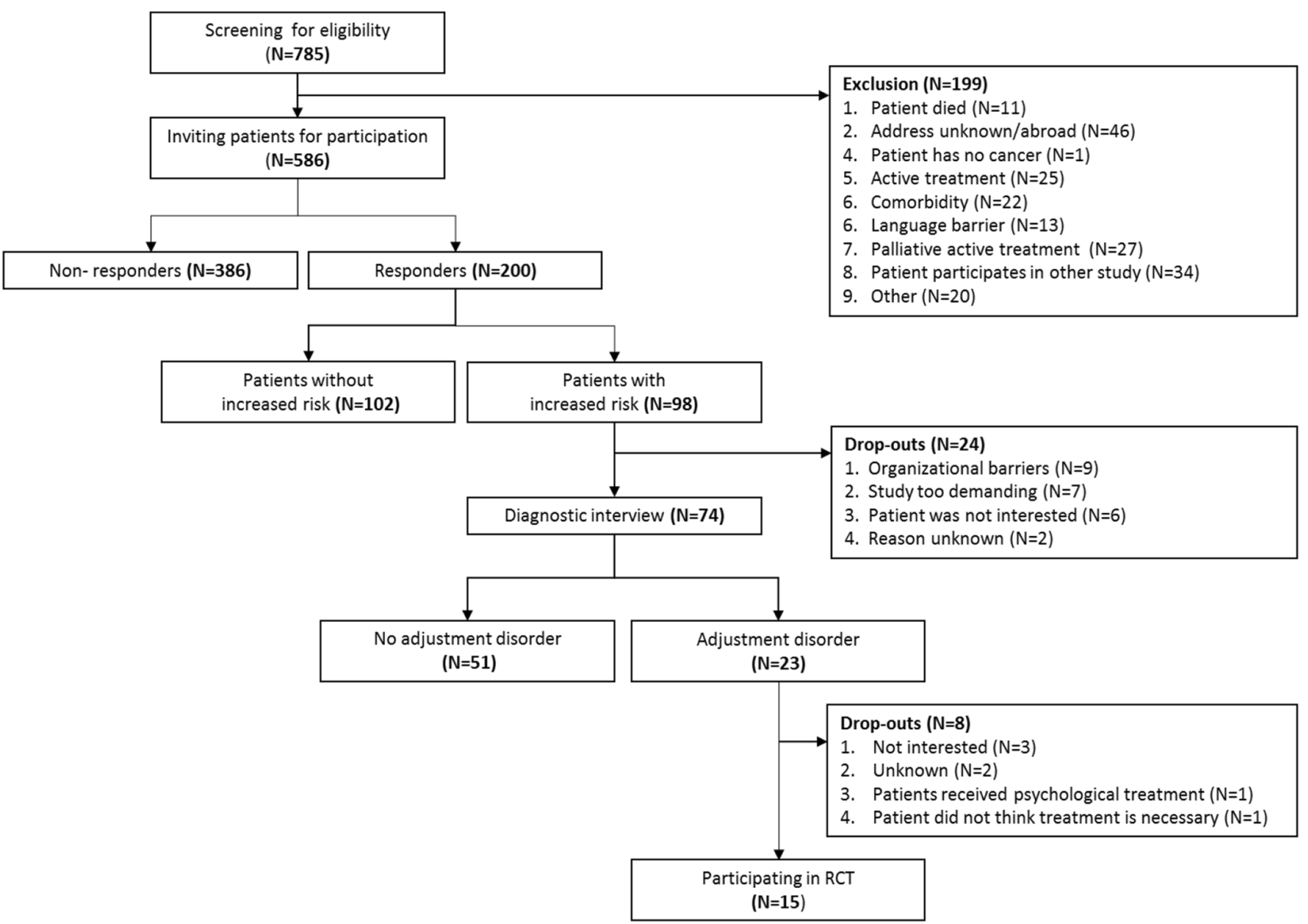

Fig. 1 Flow diagram

Characteristics of the study population $(N=200)$ are shown in Table 2.

\section{Prevalence of AD}

Of all 200 patients that completed the survey, 98 patients had an increased risk for AD (49\%) and were invited for a diagnostic interview (Figure 1). Of these 98 patients with an increased risk, 74 patients agreed to participate in a diagnostic interview (participation rate 75\%). There were no significant differences between participants and drop-outs except that patients who dropped out reported more frequently that they were not willing to talk to an expert (Table 3).

Of the 74 participants with an increased risk for AD and who participated in a diagnostic interview, 23 patients were diagnosed with AD (31\%). The overall prevalence rate of AD was estimated at $13.1 \%$. Sensitivity analyses in which the 24 patients who dropped out were all expected to have $\mathrm{AD}$, partly expected to have $\mathrm{AD}$, or all expected to have no $\mathrm{AD}$, showed prevalence rates of $23.5 \%, 15.0 \%$, and $11.5 \%$ respectively. Multivariate analysis showed that overall AD was significantly associated with employment status and time since diagnosis (Table 4). The prevalence of $\mathrm{AD}$ was higher in patients who were employed (odds ratio $(\mathrm{OR})=3.3,95 \% \mathrm{CI}=1.3-8.4)$ and higher in patients diagnosed less than 5 years ago $(\mathrm{OR}=0.3$, $95 \% \mathrm{CI}=0.1-0.8)$. Among patients who participated in the diagnostic interview $(N=74)$, AD was significantly associated with employment status, time since diagnosis, and willingness to talk to an expert (Table 4). The prevalence of $\mathrm{AD}$ was higher in patients who were employed $(\mathrm{OR}=3.2$, $95 \% \mathrm{CI}=1.3-8.4)$, patients who were diagnosed less than 5 years prior to the study $(\mathrm{OR}=0.3,95 \% \mathrm{CI}=0.007-0.9)$, and patients who were willing to talk to a psychologist or social worker $(\mathrm{OR}=9.2,95 \% \mathrm{CI}=1.9-45.6)$.

\section{Acceptance of psychological treatment}

Of all 23 patients diagnosed with $\mathrm{AD}, 15$ patients participated in the RCT (65\%) (Figure 1). Univariate analysis showed that acceptance of treatment was not significantly associated with any of the investigated factors (Table 4). 
Table 1 Characteristics of responders and non-responders

\begin{tabular}{llll}
\hline Characteristics & $\begin{array}{l}\text { Non-responders } \\
\text { Part 1 }(N=386)\end{array}$ & $\begin{array}{l}\text { Responders } \\
\text { Part 1 }(N=200)\end{array}$ & $p$-value \\
\hline $\begin{array}{l}\text { Age mean (SD) } \\
\text { Gender }\end{array}$ & $68(10)$ & $68(10)$ & 0.80 \\
$\quad$ Male & $109(28 \%)$ & $87(44 \%)$ & $<\mathbf{0 . 0 0 1}$ \\
$\quad$ Female & $277(72 \%)$ & $113(57 \%)$ & \\
Social economic status & & & \\
$\quad$ Low & $113(29 \%)$ & $39(20 \%)$ & $\mathbf{0 . 0 0 2}$ \\
$\quad$ Middle & $170(44 \%)$ & $81((41 \%)$ & \\
$\quad$ High & $103(27 \%)$ & $80(40 \%)$ & \\
Tumorsite & & & \\
$\quad$ Prostate & $49(13 \%)$ & $56(28 \%)$ & $\mathbf{0 . 0 0 1}$ \\
$\quad$ Breast & $246(64 \%)$ & $98(49 \%)$ & \\
$\quad$ Head and neck & $91(24 \%)$ & $46(23 \%)$ & \\
Tumor stage & & & \\
I-II & $316(82 \%)$ & $151(76 \%)$ & $\mathbf{0 . 0 0 1}$ \\
III-IV & $69(18 \%)$ & $49(25 \%)$ & \\
Time since diagnosis & & & \\
$\quad$ years) & & $53(27 \%)$ & \\
0-5 & $112(29 \%)$ & $146(73 \%)$ & \\
$>5$ & $274(71 \%)$ & & \\
\hline
\end{tabular}

Abbreviation: $S D$, standard deviation

Result printed in bold is significant $(P<0.05)$

\section{Discussion}

This study investigated the prevalence of AD among cancer patients and the acceptance of psychological treatment for $\mathrm{AD}$, in relation to sociodemographic, clinical, and psychological factors. Overall prevalence rate of AD was estimated at $13 \%$. Being employed and being diagnosed less than 5 years prior to the study were significantly associated with AD. It was estimated that $65 \%$ of patients with AD were willing to accept psychological treatment. None of the investigated factors was associated with acceptance of psychological treatment.

The prevalence rate of $\mathrm{AD}$ should be viewed within the light of the sensitivity analyses in which prevalence rates of $24 \%, 15 \%$, and $12 \%$ were found. As there were no significant differences in sociodemographic, clinical, and psychological characteristics, except from willingness to talk to an expert, between patients with an increased risk for AD who did and did not participate in the diagnostic interview, we assume that scenario b (i.e., prevalence of $\mathrm{AD}$ is the same among patients with an increased risk for AD who did and did not participate in the diagnostic interview) is most acceptable. Therefore, a prevalence rate of $13-15 \%$ is expected to be most plausible. The prevalence rate of $13-15 \%$ is in line with two previous studies reporting prevalence rates of $12 \%$ $[4,5]$. A previous meta-analysis showed a higher prevalence rate of $19.4 \%$ [3], and another recent study showed a prevalence rate of $17 \%$ [7]. The studies with similar prevalence rates used a comparable two-step method for diagnosing $\mathrm{AD}$ as performed in this study, albeit that they used a different screening instrument (PHQ-9) [4, 5]. Such a twostep approach has been proven to be valid and efficient [20] and is in accordance with the Dutch guideline on AD [8]. A drawback of this procedure is that patients may have been missed who had a low score on the screening questionnaires who should be diagnosed with AD. This may explain the somewhat higher prevalence rates of $17 \%$ [7] and 19\% [3] in studies in which all patients received a diagnostic interview. Another explanation may be the absence of clear criteria to diagnose $\mathrm{AD}$, as strict diagnostic criteria for $\mathrm{AD}$ in the DSM-V are lacking [21]. As a consequence, the diagnosis of AD may be prone to a psychologist's individual interpretation of the criteria.

The current study demonstrated that being employed, being diagnosed less than 5 years prior to the study, and being willing to talk to an expert are associated with AD, while sociodemographic factors as age, sex, education, and marital status, and clinical factors as cancer type, stage, and treatment were not. This is in contrast to previous studies reporting that being female, younger, unmarried, more highly educated, and diagnosed with a more advanced tumor stage are associated with $\mathrm{AD}[5,9]$. An explanation might be the relatively small sample size of our study that may have failed to detect smaller differences. Also, in our study we included breast cancer, head and neck cancer and prostate cancer patients, whereas previous studies focused on breast cancer patients only or a combination of 13 different tumor types [5, 9]. The distribution of sociodemographic and clinical characteristics such as gender, education level, and tumor stage may consequently differ among studies. Another explanation may be that in contrast to our study, in previous studies time since diagnosis and employment status were not investigated while these factors might be more important than other factors.

Cancer patients who have to manage multiple tasks (e.g., work, housekeeping, children) may perceive cancer-related stressors as a higher burden compared to those with less tasks (e.g., those who are not employed) and therefore may be more vulnerable for developing distress [22, 23] or psychiatric disorders as AD. Although the association between paid work and AD has not been reported or studied in previous research, it is largely in line with previous research that showed an association between work and psychological symptoms [24, 25]. The same holds for the association between willingness to talk to a psychologist or social worker, which has previously been demonstrated to be associated with higher psychological distress [16, 26]. The finding that shorter time since diagnosis is associated with AD confirms previous reviews showing that psychiatric disorders as well as psychological symptoms are highest 
Table 2 Characteristics study population

\begin{tabular}{|c|c|c|c|c|c|c|}
\hline & Responders $(N=200)$ & $\begin{array}{l}\text { Patients } \\
\text { without AD } \\
(N=153)\end{array}$ & $\begin{array}{l}\text { Patients with Increased } \\
\text { risk and no } \mathrm{AD}(N=51)\end{array}$ & $\begin{array}{l}\text { Patients with } \\
\mathrm{AD}(N=23)\end{array}$ & $\begin{array}{l}\text { Patients with } \\
\text { treatment } \\
(N=15)\end{array}$ & $\begin{array}{l}\text { Patient without } \\
\text { treatment } \\
(N=8)\end{array}$ \\
\hline Age mean (SD) & $68(10)$ & $69(9)$ & $68(9)$ & $63(13)$ & $62(13)$ & $63(12)$ \\
\hline \multicolumn{7}{|l|}{ Gender } \\
\hline Female & $113(57 \%)$ & $81(53 \%)$ & $27(53 \%)$ & $14(61 \%)$ & $8(53 \%)$ & $6(75 \%)$ \\
\hline \multicolumn{7}{|l|}{ Married (yes/no) } \\
\hline Yes & $136(68 \%)$ & $108(71 \%)$ & $33(65 \%)$ & $13(57 \%)$ & $8(53 \%)$ & $5(63 \%)$ \\
\hline \multicolumn{7}{|l|}{ Employment status (yes/no) } \\
\hline Yes & $49(25 \%)$ & $34(22 \%)$ & $8(16 \%)$ & $12(52 \%)$ & $8(53 \%)$ & $3(38 \%)$ \\
\hline \multicolumn{7}{|l|}{ Education (high/low) } \\
\hline High & $115(58 \%)$ & $88(58 \%)$ & $29(57 \%)$ & $12(52 \%)$ & $7(47 \%)$ & $5(63 \%)$ \\
\hline \multicolumn{7}{|l|}{ Tumor site } \\
\hline Prostate & $56(28 \%)$ & $46(30 \%)$ & $10(20 \%)$ & $4(18 \%)$ & $4(27 \%)$ & $2(25 \%)$ \\
\hline Breast & $98(49 \%)$ & $71(46 \%)$ & $26(51 \%)$ & $13(57 \%)$ & $7(47 \%)$ & $6(75 \%)$ \\
\hline Head and neck & $46(23 \%)$ & $36(24 \%)$ & $15(29 \%)$ & $6(26 \%)$ & $4(27 \%)$ & 0 \\
\hline \multicolumn{7}{|l|}{ Tumor stage (I-II/III-IV)) } \\
\hline III-IV & $49(25 \%)$ & $38(25 \%)$ & $25(49 \%)$ & $4(17 \%)$ & $3(20 \%)$ & $1(13 \%)$ \\
\hline \multicolumn{7}{|l|}{ Treatment $^{1}$} \\
\hline Single treatment & $102(51 \%)$ & $78(51 \%)$ & $26(51 \%)$ & $13(57 \%)$ & $10(67 \%)$ & $3(38 \%)$ \\
\hline Surgery & $76(38 \%)$ & $59(39 \%))$ & $19(37 \%)$ & $10(44 \%)$ & $8(53 \%)$ & $2(25 \%)$ \\
\hline Radiotherapy & $25(13 \%)$ & $18(12 \%)$ & $7(14 \%)$ & $3(13 \%)$ & $2(13 \%)$ & 0 \\
\hline Chemotherapy & $1(1 \%)$ & $1(1 \%)$ & 0 & 0 & 0 & 0 \\
\hline Multiple treatment & $96(48 \%)$ & $73(48 \%)$ & $25(49 \%)$ & $10(44 \%)$ & $5(33 \%)$ & $5(63 \%)$ \\
\hline Surgery + radiotherapy & $41(21 \%)$ & $35(23 \%)$ & $12(24 \%)$ & 0 & 0 & 0 \\
\hline Surgery + chemotherapy & $16(8 \%)$ & $10(7 \%)$ & $1(2 \%)$ & $5(22 \%)$ & $1(7 \%)$ & $4(50 \%)$ \\
\hline $\begin{array}{l}\text { Radiotherapy + chemo- } \\
\text { therapy }\end{array}$ & $12(6 \%)$ & $9(6 \%)$ & $3(6 \%)$ & $1(4 \%)$ & $1(7 \%)$ & 0 \\
\hline $\begin{array}{l}\text { Surgery + radiother- } \\
\text { apy }+ \text { chemotherapy }\end{array}$ & $27(14 \%)$ & $19(12 \%)$ & $9(18 \%)$ & $4(17 \%)$ & $3(20 \%)$ & $1(13 \%)$ \\
\hline Hormone therapy & $60(30 \%)$ & $44(29 \%)$ & $17(33 \%)$ & $12(52 \%)$ & $5(33 \%)$ & $5(63 \%)$ \\
\hline \multicolumn{7}{|l|}{$\begin{array}{l}\text { Time since diagnosis } \\
\text { (years) }\end{array}$} \\
\hline$>5$ & $145(73 \%)$ & $119(78 \%)$ & $40(78 \%)$ & $12(52 \%)$ & $6(40 \%)$ & $6(75 \%)$ \\
\hline \multicolumn{7}{|c|}{ Psychological outcome scores mean (SD) } \\
\hline HADS-T $^{1}$ & $7.4(6.9)$ & $5.5(5.7)$ & $10.8(6.4)$ & $13.9(6.9)$ & $14.3(6.6)$ & $13.3(7.7)$ \\
\hline HADS-A ${ }^{1}$ & $4.1(3.9)$ & $3.1(3.3)$ & $7.9(4.3)$ & $7.9(4.3)$ & $8.6(4.5)$ & $6.5(3.9)$ \\
\hline HADS-D ${ }^{1}$ & $3.3(3.6)$ & $2.5(3.0)$ & $2.1(3.9)$ & $6.1(3.9))$ & $5.7(3.5)$ & $6.8(4.6)$ \\
\hline $\mathrm{DT}^{1}$ & $3.6(2.8)$ & $2.7(2.6)$ & $5.7(6.0)$ & $6.5(1.9)$ & $6.6(1.5)$ & $6.4(2.4)$ \\
\hline $\mathrm{CIS}^{1}$ & $58.8(29.4)$ & $54.6(25.9)$ & $75.2(24.4)$ & $81.7(27.8)$ & $83.6(26.0)$ & $77.8(33.0)$ \\
\hline \multicolumn{7}{|l|}{ Items on problem list (yes) } \\
\hline Practical problems & $71(36 \%)$ & $44(29 \%)$ & $29(57 \%)$ & $13(57 \%)$ & $9(60 \%)$ & $4(50 \%)$ \\
\hline Family and social & $30(15 \%)$ & $17(11 \%)$ & $10(20 \%)$ & $8(35 \%)$ & $5(33 \%)$ & $3(38 \%)$ \\
\hline Emotional & $111(56 \%)$ & $81(52 \%)$ & $41(80 \%)$ & $19(83 \%)$ & $14(93 \%)$ & $5(63 \%)$ \\
\hline Religious or spiritual & $39(20 \%)$ & $23(15 \%)$ & $12(24 \%)$ & $8(35 \%)$ & $5(33 \%)$ & $3(38 \%)$ \\
\hline Physical & $163(82 \%)$ & $117(77 \%)$ & $50(98 \%)$ & $22(96 \%)$ & $14(93 \%)$ & $8(100 \%)$ \\
\hline \multicolumn{7}{|c|}{ Willingness to talk to an expert ${ }^{1}$} \\
\hline Yes/maybe & $66(33 \%)$ & $39(26 \%)$ & $25(49 \%)$ & $21(91 \%)$ & $14(93 \%)$ & $7(88 \%)$ \\
\hline
\end{tabular}

Abbreviations: $A D$, adjustment disorder; $C I S$, Checklist Individual Strength; $D T$, distress thermometer; HADS, Hospital Anxiety and Depression Scale; $-A$, anxiety subscale; $-D$, depression subscale; $-T$, total score

${ }^{1}$ Missing data: treatment (2), HADS-T (2), HADS-A (1), HADS-D (1), DT (1), CIS (6), willingness to talk (1) 
Table 3 Characteristics of patients with an increased risk for AD who did and did not participate in the diagnostic interview

\begin{tabular}{|c|c|c|c|}
\hline Characteristics & $\begin{array}{l}\text { Patients with an increased risk who } \\
\text { had an interview in part } 2(N=74)\end{array}$ & $\begin{array}{l}\text { Drop-outs } \\
\text { part } 2 \\
(N=24)\end{array}$ & $p$-value \\
\hline Age mean (SD) & $66(11)$ & $67(11)$ & 0.63 \\
\hline Gender & & & 0.09 \\
\hline Female & $41(55 \%)$ & $18(75 \%)$ & \\
\hline Married (yes/no) & & & 0.98 \\
\hline Yes & $28(38 \%)$ & $15(63 \%)$ & \\
\hline Employed (yes/no) & & & 0.37 \\
\hline Yes & $19(26 \%)$ & $4(17 \%)$ & \\
\hline Education (high/low) & & & 0.54 \\
\hline High & $41(55 \%)$ & $15(63 \%)$ & \\
\hline Tumor site & & & 0.85 \\
\hline Prostate & $16(22 \%)$ & $4(17 \%)$ & \\
\hline Breast & $39(53 \%)$ & $14(58 \%)$ & \\
\hline Head and neck & $19(26 \%)$ & $6(25 \%)$ & \\
\hline Tumor stage (I-II/III-IV) & & & 0.64 \\
\hline III-IV & $16(22 \%)$ & $13(54 \%)$ & \\
\hline Treatment & & & 0.56 \\
\hline Single treatment & $39(53 \%)$ & $11(46 \%)$ & \\
\hline Surgery & $29(39 \%)$ & $7(29 \%)$ & \\
\hline Radiotherapy & $10(14 \%)$ & $4(17 \%)$ & \\
\hline Chemotherapy & 0 & 0 & \\
\hline Multiple treatment & $35(47 \%)$ & $13(54 \%)$ & \\
\hline Surgery + radiotherapy & $12(16 \%)$ & $6(25 \%)$ & \\
\hline Surgery + chemotherapy & $6(8 \%)$ & $1(4 \%)$ & \\
\hline Radiotherapy + chemotherapy & $4(5 \%)$ & $2(8 \%)$ & \\
\hline Surgery + radiotherapy + chemotherapy & $13(18 \%)$ & $4(17 \%)$ & \\
\hline Hormone therapy & $27(37 \%)$ & $6(25 \%)$ & 0.30 \\
\hline Time since diagnosis (years) & & & 0.74 \\
\hline$>5$ & $52(70 \%)$ & $16(67 \%)$ & \\
\hline \multicolumn{4}{|l|}{ Psychological outcome mean (SD) } \\
\hline HADS-T & $11.9(3.7)$ & $13.0(7.3)$ & \\
\hline HADS-A & $6.5(4.0)$ & $7.0(3.8)$ & 0.59 \\
\hline HADS-D & $5.4(3.6)$ & $6.0(4.4)$ & 0.50 \\
\hline DT & $5.9(6.0)$ & $6.1(1.4)$ & 0.65 \\
\hline CIS & $77.6(25.4)$ & $84.0(28.2)$ & 0.27 \\
\hline \multicolumn{4}{|l|}{ Items on problem list (yes) } \\
\hline Practical problems & $42(57 \%)$ & $14(58 \%)$ & 0.89 \\
\hline Family and social & $18(24 \%)$ & $5(21 \%)$ & 0.73 \\
\hline Emotional & $60(81 \%)$ & $20(83 \%)$ & 0.80 \\
\hline Religious or spiritual & $20(27 \%)$ & $8(33 \%)$ & 0.55 \\
\hline Physical & $72(97 \%)$ & $24(100 \%)$ & 0.41 \\
\hline \multicolumn{4}{|l|}{ Willingness to talk to an expert } \\
\hline Yes/maybe & $46(62 \%)$ & $6(25 \%)$ & 0.002 \\
\hline
\end{tabular}

Abbreviations: $A D$, adjustment disorder; $C I S$, Checklist Individual Strength; $D T$, distress thermometer; $H A D S$, Hospital Anxiety and Depression Scale; $-A$, anxiety subscale; $-D$, depression subscale; $-T$, total score; $S D$, standard deviation

Result printed in bold is significant $(P<0.05)$ at time since diagnosis and slightly decrease over time [3, 27]. However, there are no longitudinal studies investigating $\mathrm{AD}$ over time, so further research is needed to investigate whether AD decreases, increases, or fluctuates over time. Longitudinal research may also clarify whether AD should be regarded as a transient diagnosis or as a disorder that 
Table 4 Variables associated with AD and acceptance of psychological treatment

\begin{tabular}{|c|c|c|c|c|c|}
\hline \multirow[t]{2}{*}{ Variables } & \multicolumn{2}{|c|}{ Presence of $\mathrm{AD}$ among all patients $(N=176)$} & \multicolumn{2}{|c|}{$\begin{array}{l}\text { Presence of } \mathrm{AD} \text { among patients with } \\
\text { increased risk }(N=74)\end{array}$} & \multirow{2}{*}{$\begin{array}{l}\text { Acceptance of psy- } \\
\text { chological treatment } \\
\text { among patients with } \\
\text { AD }(N=23) \\
\text { Univariate OR }[95 \% \mathrm{CI}]\end{array}$} \\
\hline & $\begin{array}{l}\text { Univariate OR } \\
{[95 \% \mathrm{CI}]}\end{array}$ & $\begin{array}{l}\text { Multivariate OR } \\
{[95 \% \mathrm{CI}]}\end{array}$ & $\begin{array}{l}\text { Univariate OR } \\
{[95 \% \mathrm{CI}]}\end{array}$ & $\begin{array}{l}\text { Multivariate OR } \\
{[95 \% \mathrm{CI}]}\end{array}$ & \\
\hline \multicolumn{6}{|c|}{ Clinical and demographic } \\
\hline Mean age & $0.9[0.9-1.0]$ & & $1.0[0.9-1.0]$ & & $1.0[0.9-1.1]$ \\
\hline $\begin{array}{l}\text { Gender (refer- } \\
\text { ence }=\text { male) }\end{array}$ & $1.4[0.6-3.9]$ & & $1.4[0.5-3.8]$ & & $0.4[0.1-2.5]$ \\
\hline $\begin{array}{l}\text { Marital status } \\
(\text { reference }=\text { no } \\
\text { marital status })\end{array}$ & $0.5[0.2-1.3]$ & & $0.7[0.3-1.9]$ & & $0.7[0.1-4.0]$ \\
\hline $\begin{array}{l}\text { Employment status } \\
\text { (references = no } \\
\text { employment } \\
\text { status) }\end{array}$ & $3.2[1.3-7.9]^{* *}$ & $3.4[1.3-8.5]^{* *}$ & $4.9[1.6-15.0]^{*}$ & $4.4[1.2-16.01]^{*}$ & $1.9[0.3-11.0]$ \\
\hline $\begin{array}{l}\text { Education (refer- } \\
\text { ence }=\text { lower) }\end{array}$ & $0.8[0.3-1.9]$ & & $0.8[0.3-2.2]$ & & $0.5[0.1-3.0]$ \\
\hline \multicolumn{6}{|c|}{ Tumor site $($ reference $=$ prostate $)$} \\
\hline Breast & $1.4[0.5-4.0]$ & & $0.8[<0.01-2.0]$ & & $\mathrm{N}^{\prime} \mathrm{A}^{1}$ \\
\hline Head and neck & $0.9[0.2-3.3]$ & & $0.4[0.2-2.8]$ & & N/A ${ }^{1}$ \\
\hline $\begin{array}{l}\text { Tumor stage (ref- } \\
\text { erence }=\text { I-II) }\end{array}$ & $0.6[0.2-1.9]$ & & $0.6[0.2-1.9]$ & & $1.8[0.2-20.2]$ \\
\hline $\begin{array}{l}\text { Treatment (refer- } \\
\text { ence }=\text { single) }\end{array}$ & $0.8[0.3-2.0]$ & & $0.8[0.3-2.2]$ & & $0.3[0.1-1.8]$ \\
\hline $\begin{array}{l}\text { Years since } \\
\text { diagnosis (refer- } \\
\text { ence }=0-5 \text { ) }\end{array}$ & $0.3[0.1-0.8]^{* *}$ & $0.3[0.1-0.8]^{* *}$ & $0.3[0.1-0.9]^{*}$ & $0.3[0.07-0.9]^{*}$ & $0.2[<0.1-1.5]$ \\
\hline \multicolumn{6}{|l|}{ Psychological outcomes } \\
\hline HADS-T & & & $1.1[1.0-1.2]$ & & $1.0[0.9-1.2]$ \\
\hline HADS-A & & & $1.1[1.0-1.3]$ & & $1.1[0.9-1.4]$ \\
\hline HADS-D & & & $1.1[0.9-1.2]$ & & $0.9[0.7-1.2]$ \\
\hline DT & & & $1.3[1.0-1.6]$ & & $1.1[0.7-1.7]$ \\
\hline CIS & & & $1.0[1.0-1.0]$ & & $1.0[1.0-1.0]$ \\
\hline \multicolumn{6}{|c|}{ Items on problem list $($ reference $=$ no $)$} \\
\hline Practical & & & $1.0[0.4-2.7]$ & & $1.5[0.3-8.4]$ \\
\hline Family and social & & & $2.2[0.7-6.9]$ & & $0.8[0.1-5.0]$ \\
\hline Emotional & & & $1.2[0.3-4.2]$ & & $8.4[0.7-100.6]$ \\
\hline $\begin{array}{l}\text { Religious or } \\
\text { spiritual }\end{array}$ & & & $1.7[0.6-5.1]$ & & $0.8[0.1-5.0]$ \\
\hline Physical & & & $0.4[0.03-7.3]$ & & N/A ${ }^{1}$ \\
\hline $\begin{array}{l}\text { Willingness to talk } \\
\text { to an expert }\end{array}$ & & & $10.9[2.3-51.5]^{*}$ & $9.2[1.9-45.6]^{*}$ & $2.0[0.1-37.0]$ \\
\hline
\end{tabular}

Abbreviations: $A D$, adjustment disorder; $C I S$, Checklist Individual Strength; $D T$, distress thermometer; HADS, Hospital Anxiety and Depression Scale; - $A$, anxiety subscale; $-D$, depression subscale; $-T$, total score; $O R$, odds ratio; $C I$, confidence interval

${ }^{1}$ Analyses reported with "N/A" were not applicable due to limited sample size

* $p$-value $<0.05, * * p$-value $<0.01$

Results printed in bold are significant $(P<0.05)$

should be treated to prevent a shift to another type of diagnosis (e.g., depression disorder) [28, 29].

Of the 23 patients diagnosed with AD in our study, $65 \%$ were willing to participate in an RCT on the effectiveness and cost-utility of psychological treatment for $\mathrm{AD}$, and accepted psychological treatment. This is in line with the results of the meta-analysis of Brebach et al. [10] who found a pooled usage rate of $60 \%$ for psychological treatment among cancer 
patients. Brebach et al. [10] suggested that the possibility of assignment to a non-intervention group, and interventions delivered by telephone compared to face-to-face increased the usage of psychological interventions. A recent qualitative study showed that, from the patient's perspective, the organization of psychological treatment targeting cancer patients should focus on easy accessibility and availability, delivery by specialized psychologists, and integration in medical cancer care. Online and group therapy are acceptable, but individual face-to-face therapy is preferred [30]. We did not find factors associated with the acceptance of psychological treatment in the current study, which is possibly due to the limited statistical power. Further quantitative research is needed to investigate factors associated with the acceptance of psychological treatment for $\mathrm{AD}$ [10-12].

\section{Study limitations}

A strength of our study is the two-step approach to diagnose AD. A limitation is that, due to the COVID-19 pandemic, we had to stop recruiting patients earlier than planned, which resulted in 200 patients with breast, prostate, and head and neck cancer instead of the planned 3000 patients with various types of cancer [14]. The low response rate of $34 \%$, and significant differences between the responders and non-responders might also limit the representativeness of this study. Another limitation is that the included patients were comparatively older and time since diagnosis was relatively longer. Finally, the results of this study are applicable to the situation before the COVID-19 pandemic. The prevalence of AD and acceptance of psychological treatment might be different during or after this pandemic. Nevertheless, the findings in this study can serve as benchmark for future studies investigating $\mathrm{AD}$ and the acceptance of psychological treatment among cancer patients.

\section{Clinical implications}

As the prevalence of AD is substantial and acceptance of psychological treatment is high, implementation of screening procedures to identify patients with $\mathrm{AD}$ in routine care is recommended. However, effectiveness and cost-effectiveness of psychological treatment of AD remain to be answered. An ongoing RCT will provide more evidence [14]. Further research should also focus on barriers to accept psychological treatment among cancer patients with $\mathrm{AD}$ as there is still a large gap between patients who may need treatment and patients who actually accept and use psychological treatment.

\section{Conclusion}

The prevalence of $\mathrm{AD}$ among cancer patients is estimated at 13 to $15 \%$. AD among all cancer patients was found to be significantly associated with being employed and shorter time since diagnosis. AD among cancer patients who participated in the diagnostic interview was found to be significantly associated with being employed, shorter time since diagnosis and willingness to talk to an expert. The majority of cancer patients with $\mathrm{AD}$ accept psychological treatment.

Acknowledgements We would like to thank Fabienne Drost, Davyenne Theunissen, Willianne Westerduin, Esther ter Borg, Sascha Baron, Nienke Tielemans, and Bettina Sari for their help with the diagnostic interviews.

Author contribution FB: conceptualization, methodology, investigation, analyzing data, writing original draft. LW: conceptualization, methodology, investigating, review and editing original draft. JC: methodology, investigating, review and editing original draft. $\mathrm{KH}$ : investigation, review and editing original draft. BR: analyzing data, review and editing original draft. $\mathrm{NH}$ : investigation, review and editing original draft. EA: investigation, review and editing original draft, SV: investigation, review and editing original draft. SE: recruitment, review and editing original draft. LS: recruitment, review and editing original draft. IO: recruitment, review and editing original draft. MV: recruitment, review and editing original draft. JP: conceptualization, methodology, investigation, review and editing, supervision, funding acquisition. IV: conceptualization, methodology, investigation, review and editing, supervision, funding acquisition. FJ: conceptualization, methodology, investigation, analyzing data, review and editing, supervision. All authors have approved the final manuscript.

Funding This research is funded by ZonMw, The Netherlands Organization for Health [grant number: 856001005]. The funding source had no role in the study design, collection, analysis or interpretation of the data, writing the manuscript, or the decision to submit the paper for publication.

Data availability The datasets generated during and analyzed during the current study are available from the corresponding author on reasonable request.

Code availability Not applicable.

\section{Declarations}

Ethics approval This study was performed in line with the principles of the Declaration of Helsinki. Study procedures were approved by the Medical Ethical Committee of VUmc (registry number 2018.524 and 2019.002).

Consent to participate All patients signed consent form prior to their participation.

Consent for publication Not required.

Conflict of interest The authors declare no competing interests.

Open Access This article is licensed under a Creative Commons Attribution 4.0 International License, which permits use, sharing, adaptation, distribution and reproduction in any medium or format, as long as you give appropriate credit to the original author(s) and the source, provide a link to the Creative Commons licence, and indicate if changes were made. The images or other third party material in this article are included in the article's Creative Commons licence, unless indicated otherwise in a credit line to the material. If material is not included in 
the article's Creative Commons licence and your intended use is not permitted by statutory regulation or exceeds the permitted use, you will need to obtain permission directly from the copyright holder. To view a copy of this licence, visit http://creativecommons.org/licenses/by/4.0/.

\section{References}

1. Stein KD, Syrjala KL, Andrykowski MA (2008) Physical and psychological long-term and late effects of cancer. Cancer 112:25772592. https://doi.org/10.1002/cncr.23448

2. Nuckols CC, Nuckols CC (2013) The diagnostic and statistical manual of mental disorders, (DSM-5). American Psychiatric Association, Philadelphia

3. Mitchell AJ, Chan M, Bhatti H, Halton M, Grassi L, Johansen C et al (2011) Prevalence of depression, anxiety, and adjustment disorder in oncological, haematological, and palliative-care settings: a meta-analysis of 94 interview-based studies. Lancet Oncol 12:160-174. https://doi.org/10.1016/S1470-2045(11)70002-X

4. Mehnert A, Brähler E, Faller H, Härter M, Keller M, Schulz H et al (2014) Four-week prevalence of mental disorders in patients with cancer across major tumor entities. J Clin Oncol 32:3540 3546. https://doi.org/10.1200/JCO.2014.56.0086

5. Hund B, Reuter K, Härter M, Brähler E, Faller H, Keller M et al (2016) Stressors, symptom profile, and predictors of adjustment disorder in cancer patients. Results from an epidemiological study with the Composite International Diagnostic Interview, adaptation for oncology (CIDI-O). Depress Anxiety 33:153-161. https://doi. org/10.1002/da.22441

6. Blázquez MH, Cruzado JA (2016) A longitudinal study on anxiety, depressive and adjustment disorder, suicide ideation and symptoms of emotional distress in patients with cancer undergoing radiotherapy. J Psychosom Res 87:14-21. https://doi.org/10. 1016/j.jpsychores.2016.05.010

7. Singer S, Meyer A, Wienholz S, Briest S, Brown A, Dietz A et al (2014) Early retirement in cancer patients with or without comorbid mental health conditions: a prospective cohort study. Cancer 120:2199-2206. https://doi.org/10.1002/cncr.28716

8. Trimbos (2016) [Guidelines adjustment disorder in cancer patients]. Available via trimbos.nl. Accessed 21 march 2021

9. Tang H-Y, Xiong H-H, Deng L-C, Fang Y-X, Zhang J, Meng $\mathrm{H}$ (2020) Adjustment disorder in female breast cancer patients: prevalence and its accessory symptoms. Future 18:19. https://doi. org/10.1007/s11596-020-2205-1

10. Brebach R, Sharpe L, Costa DS, Rhodes P, Butow P (2016) Psychological intervention targeting distress for cancer patients: a meta-analytic study investigating uptake and adherence. Psychooncology 25:882-890. https://doi.org/10.1002/pon.4099

11. Faller H, Weis J, Koch U, Brähler E, Härter M, Keller M et al (2017) Utilization of professional psychological care in a large German sample of cancer patients. Psychooncology 26:537-543. https://doi.org/10.1002/pon.4197

12. Salmon P, Clark L, McGrath E, Fisher P (2015) Screening for psychological distress in cancer: renewing the research agenda. Psychooncology 24:262-268. https://doi.org/10.1002/pon.3640

13. Carlson LE, Waller A, Mitchell AJ (2012) Screening for distress and unmet needs in patients with cancer: review and recommendations. J Clin Oncol 30:1160-1177. https://doi.org/10.1200/JCO. 2011.39.5509

14. Van Beek FE, Wijnhoven LM, Jansen F, Custers JA, Aukema EJ, Coupé VM et al (2019) Prevalence of adjustment disorder among cancer patients, and the reach, effectiveness, cost-utility and budget impact of tailored psychological treatment: study protocol of a randomized controlled trial. BMC psychology 7:1-11. https:// doi.org/10.1186/s40359-019-0368-y

15. Spinhoven P, Ormel J, Sloekers P, Kempen G, Speckens A, Van Hemert A (1997) A validation study of the Hospital Anxiety and Depression Scale (HADS) in different groups of Dutch subjects. Psychol Med 27:363-370. https://doi.org/10.1017/S003329179 6004382

16. Tuinman MA, Gazendam-Donofrio SM, Hoekstra-Weebers JE (2008) Screening and referral for psychosocial distress in oncologic practice: use of the Distress Thermometer. Cancer 113:870 8. https://doi.org/10.1002/cncr.23622

17. Workgroup adjustment disorders (2017) [Indication Adjustment disorder in cancer patients]. The Netherlands Organisation for Health Research and Development (ZonMw). Richtlijn - Aanpassingsstoornis bij patiënten met kanker (zonmw.nl)

18. Worm-Smeitink M, Gielissen M, Bloot L, Van Laarhoven H, Van Engelen B, Van Riel P et al (2017) The assessment of fatigue: Psychometric qualities and norms for the Checklist individual strength. J Psychosom Res 98:40-46. https://doi.org/10.1016/j. jpsychores.2017.05.007

19. Vercoulen J, Alberts M, Bleijenberg G (1999) Checklist Individual Strength (CIS). Gedragstherapie 32:6

20. Jacobi F, Wittchen H-U, Hölting C, Höfler M, Pfister H, Müller $\mathrm{N}$ et al (2004) Prevalence, co-morbidity and correlates of mental disorders in the general population: results from the German Health Interview and Examination Survey (GHS). Psychol Med 34:597. https://doi.org/10.1017/S0033291703001399

21. Baumeister H, Maercker A, Casey P (2009) Adjustment disorder with depressed mood. Psychopathology 42:139-147. https://doi. org/10.1159/000207455

22. Erikson EH (1994) Identity and the life cycle: WW Norton \& Company

23. Slater CL (2003) Generativity versus stagnation: an elaboration of Erikson's adult stage of human development. J Adult Dev 10:53-65

24. Semple CJ, McCance T (2010) Parents' experience of cancer who have young children: a literature review. Cancer Nurs 33:110-118. https://doi.org/10.1097/NCC.0b013e3181c024bb

25. Mehnert A (2011) Employment and work-related issues in cancer survivors. Crit Rev Oncol Hematol 77:109-130. https://doi.org/ 10.1016/j.critrevonc.2010.01.004

26. Baker-Glenn EA, Park B, Granger L, Symonds P (2011) Mitchell AJ (2011) Desire for psychological support in cancer patients with depression or distress: validation of a simple help question. Psychooncology 20:525-531. https://doi.org/10.1002/pon.1759

27. Krebber A, Buffart L, Kleijn G, Riepma I, De Bree R, Leemans C et al (2014) (2014) Prevalence of depression in cancer patients: a meta-analysis of diagnostic interviews and self-report instruments. Psychooncology 23:121-130. https://doi.org/10.1002/pon.3409

28. Takei N, Sugihara G (2006) Diagnostic ambiguity of subthreshold depression: minor depression vs adjustment disorder with depressive mood. Acta Psychiatrica Scandinavica. 114:144. https://doi. org/10.1111/j.1600-0447.2006.00802.x

29. Kendler KS, Karkowski LM, Prescott CA (1999) Causal relationship between stressful life events and the onset of major depression. Am J Psychiatry 156:837-841. https://doi.org/10.1176/ajp. 156.6.837

30. Schuit AS, Holtmaat K, Van Zwieten V, Aukema EJ, Gransier L, Cuijpers P et al (2021) Organizing psycho-oncological care for cancer patients: the patient's perspective. Front Psychol 12:1155. https://doi.org/10.3389/fpsyg.2021.62511710.3389/fpsyg.2021. 625117

Publisher's note Springer Nature remains neutral with regard to jurisdictional claims in published maps and institutional affiliations. 